\title{
TEBHIDSAL IDTSES
}

\section{A Comparison of In Vitro and In Vivo Feed Digestibility by White-tailed Deer}

\section{LEONARD F. RUGGIERO AND JAMES B. WHELAN}

Highlight: Two captive, rumen-fistulated, white-tailed deer (Odocoileus virginianus) were used to evaluate the two-stage in vitro microdigestion technique as an estimator of in vivo dry-matter digestibility. The technique provided digestibility percentages that departed only slightly from in vivo values for the artificial ration tested.

Of great importance to the Virginia Cooperative Wildlife Research Unit and the Southeastern Forest Experiment Station is the use of an in vitro microdigestion procedure as a means of evaluating quality of plants selected by deer. The advantage of the in vitro technique is that it permits rapid, inexpensive analysis of large numbers of samples. Microdigestion data are useful if they are in close agreement with in vivo macrodigestion data. Blaxter (1962) obtained such agreement in studies with domestic sheep.

\section{Methods}

Two 17-month-old, rumen-fistulated, white-tailed deer (one doe and one castrated buck) were used in a conventional digestion trial. The deer were housed in $12^{\prime} \times 20^{\prime}$ concrete-floored pens and were fed ad libitum a standard ration (Table 1) in pelleted form for 14 days. During the last 9 days of the 14-day feeding period, daily consumption of feed was recorded to the nearest gram for each deer, and a total collection of the daily fecal output from each deer was made. All pellets were carefully collected from the floor of the pens at regular intervals throughout the day in an effort to make an accurate total collection. Each day the floors of both pens were thoroughly washed to further insure an accurate collection of the daily total fecal output.

Using Pearson's (1970) method, the dry-matter digestibility of the standard ration was determined in vitro from two trials each consisting of eight repetitions. These results were compared to the in vivo estimates of dry-matter digestibility

Authors are with the Institute of Ecology, Utah State University, Logan, and Virginia Cooperative Wild life Research Unit, Virginia Polytechnic Institute and State University, Blacksburg.

This research was supported by the Virginia Cooperative Wildlife Research Unit and the Virginia Commission of Game and Inland Fisheries. Critical review by John Malecheck and Phillip Urness of the Department of Range Science at Utah State University was greatly appreciated.

Manuscript received April 12, 1975.
Table 1. Composition (\%) of standard pelleted deer ration fed to rumen-fistulated white-tailed deer during a 14 -day digestion trial.

\begin{tabular}{ll}
\hline Item & Composition (\%) \\
\hline Ingredients & 14.0 \\
Corn & 15.0 \\
Soybean oil meal & 30.0 \\
Alfalfa meal & 6.0 \\
Wheat bran & 24.0 \\
Oats & 8.0 \\
Molasses $^{1}$ & .75 \\
PO $^{1}$ & 1.50 \\
Mineral salts $^{2}$ & .01 \\
DSVP' & \\
& \\
Proximate analysis & \\
Crude protein & 19.06 \\
Ether extract & 2.97 \\
Crude fiber & 15.27 \\
Ash & 8.29 \\
Nitrogen-free extract & 54.41 \\
\hline
\end{tabular}

i Phosphate suppmement: defluorinated rock phosphate.

${ }^{2}$ Dairy supplement vitamin package (DSVP): $\mathrm{S}=1.4 \% ; \mathrm{Mg}=7.5 \%$; $\mathrm{Fe}=2.1 \% ; \mathrm{Mn}=1.3 \% ; \mathrm{Zn}=1.3 \% ; \mathrm{Cu}=0.2 \% ; \mathrm{I}=0.02 \% ; \mathrm{Co}=0.02 \% ;$ vitamin $\mathrm{A}=1.1 \times 10^{6} \mathrm{USP} / \mathrm{kg}$; vitamin $\mathrm{D}=4.4 \times 10^{5} \mathrm{USP} / \mathrm{kg}$; vitamin $\mathrm{E}=220$ $\mathrm{IU} / \mathrm{kg}$.

${ }^{3}$ Expressed as percent of ration dry matter $(90.19 \%)$.

for the standard ration obtained during a 9-day feeding period. The in vivo estimates were calculated using the following formula:

$$
\text { Percent dry matter digestibility }=\frac{\text { intake }- \text { output }}{\text { intake }} \times 100
$$

Intake and output in the above equation is expressed as grams of oven-dried matter in the ration and in the feces, respectively.

\section{Results and Discussion}

Table 2 shows the relationship between in vivo (true) and in vitro (estimated) digestibility of the pelleted ration fed to fistulated deer. This table represents data on feed consumption, total daily fecal output, and digestibility percentages from in vivo digestion trials.

The results show a close relationship between in vitro and in vivo dry-matter apparent digestibility for the ration used in 
Table 2. Means \pm SD of in vitro and in vivo dry matter digestibility of a pelleted ration fed to two 17-month-old (rumen-fistulated) white-tailed deer. ${ }^{1}$

\begin{tabular}{|c|c|c|c|c|c|}
\hline \multirow[b]{2}{*}{ Animals } & \multirow{2}{*}{$\begin{array}{c}\text { Feed } \\
\text { intake } \\
(\mathrm{g})\end{array}$} & \multirow{2}{*}{$\begin{array}{c}\text { Total fecal } \\
\text { output } \\
(\mathrm{g})\end{array}$} & \multirow{2}{*}{$\begin{array}{l}\text { In vivo } \\
\text { digestion } \\
(\%)\end{array}$} & \multicolumn{2}{|c|}{ In vitro digestion ${ }^{3}$} \\
\hline & & & & Trial & Trial 2 \\
\hline Female & $1034 \pm 140$ & $311 \pm 52$ & $69.2 \pm 3.2$ & $65.4 \pm 6.0$ & $69.6 \pm 11.7$ \\
\hline Male & $1789+375$ & $445 \pm 93$ & $73.2 \pm 8.8$ & $61.5 \pm 8.7$ & $72.9 \pm 4.2$ \\
\hline
\end{tabular}

this study. The poorest in vitro estimate was $86.3 \%$ of the corresponding in vivo value while the best estimate was $99.7 \%$. The mean estimate was $94.7 \%$. These figures indicate that this in vitro technique yielded accurate estimates of in vivo digestion, and the results appear to be repeatable. Errors in estimating in vivo digestibility by using Pearson's method were approximately $\pm 5 \%$.

\section{Literature Cited}

Blaxter, K. L. 1962. The energy metabolism of ruminants. Hutchinson and Co., Ltd. London. 329 p.

Pearson, H. A. 1970. Digestibility trials: in vitro techniques. p. 85-92. In: Range and wild life Habitat Evaluation. A research symposium. U.S. Dep. Agr., Misc. Pub. No. 1147. 